Review Article

\title{
Exercise Intervention Associated with Cognitive Improvement in Alzheimer's Disease
}

\author{
Meng Ying Cui, Yang Lin, Ji Yao Sheng ${ }^{(}$, Xuewen Zhang ${ }^{(D)}$, and Ran Ji Cui \\ Jilin Provincial Key Laboratory on Molecular and Chemical Genetic, The Second Hospital of Jilin University, 218 Ziqiang Street, \\ Changchun 130041, China \\ Correspondence should be addressed to Ran Ji Cui; cuiranji@jlu.edu.cn
}

Received 6 November 2017; Accepted 16 January 2018; Published 11 March 2018

Academic Editor: Weina Liu

Copyright ( 2018 Meng Ying Cui et al. This is an open access article distributed under the Creative Commons Attribution License, which permits unrestricted use, distribution, and reproduction in any medium, provided the original work is properly cited.

\begin{abstract}
Alzheimer's disease (AD) is a progressive neurodegenerative disease with the syndrome of cognitive and functional decline. Pharmacotherapy has always been in a dominant position for the treatment of AD. However, in most cases, drug therapy is accompanied with clinical delays when older adults have suffered from cognitive decline in episodic memory, working memory, and executive function. On the other hand, accumulating evidence suggests that exercise intervention may ameliorate the progression of cognitive impairment in aging ones while the standard strategy is lacking based on different levels of cognitive decline especially in mild cognitive impairment (MCI) and $\mathrm{AD} . \mathrm{MCI}$ is the preclinical stage of $\mathrm{AD}$ in which neurodegeneration may be reversed via neuroplasticity. Therefore, taking exercise intervention in the early stage of MCI and healthy aging at the risk of $\mathrm{AD}$ could slow down the process of cognitive impairment and provide a promising cost-effective nonpharmacological therapy to dementia.
\end{abstract}

\section{Introduction}

Demographic changes make dementia an intractable social problem, and strategies for maintaining cognitive function with the growth of the age are seriously needed. Older adults complain of subjective gradual cognitive decline, and some of them are likely to develop dementia without efficient intervention. Alzheimer's disease $(\mathrm{AD})$ and other dementias have a huge impact on the people with the disease, and taking care of them is a huge task for their families. Alzheimer's disease is becoming the fifth leading cause of death in people older than 65 years [1], and there will be 115 million people worldwide who will suffer from AD by 2050 [2]. Currently, AD is diagnosed through insoluble amyloid $\beta$-peptide $(\mathrm{A} \beta)$ in extracellular plaques and agminated tau protein in the intracellular neurofibrillary tangles by the detection of postmortem $[3,4]$.

Pharmacological and exercise therapies are the major intervention targets of AD. Cholinesterase inhibitors (donepezil, galantamine, and rivastigmine), memantine, and vitamin $\mathrm{E}$ have shown at least some efficacy in cognitive and functional decline $[5,6]$. However, there has been no definite evidence in favor of the appropriate duration and the progression of disease when drug discontinuance. Drug treatment is always a challenge because of its great cost obviously. On the other hand, a growing base of evidence has indicated that exercise interventions enhance neuroplasticity, improve cognitive function and the ability of daily life, and reduce rates of neuropsychiatric symptoms. The mechanisms of exercise for improving cognition appear to be complex and unclear, including increased blood volume and capillarization $[7,8]$, decreased reactive oxygen species (ROS) and oxidative stress [9], reduced $\mathrm{A} \beta$ load and the levels of hyperphosphorylated tau proteins $[10,11]$, the modulation of cholinergic system [12], and the regulation of expression of brain-derived neurotrophic factor [13]. A six-month randomized trial using resistance training and aerobic training finds functional changes in three regions of cortex and hemodynamic activity in the lingual gyrus [7]; Guiney et al. confirmed that exercise-related cognitive benefits point to cerebral blood flow (CBF) and cerebrovascular regulation [8]; Smith et al. found a significant decrease in activation intensity of eleven brain regions by fMRI after a 
12-week supervised treadmill walking, which suggests exercise intervention enhances neural efficiency [14]. In addition, exergaming leads to an increase of brain-derived neurotropic factor (BDNF) after cyber cycling [15], indicating that exercise benefits cognition by modulating neuronal plasticity through the regulation of dose-dependent BDNF [16]. Exercise-induced reduction of inflammatory markers (CRP, TNF- $\alpha$, and IL-6) is probably one of its molecular mechanisms as well. These trials have generally demonstrated exercise a promising treatment for AD. This review (1) highlights the importance of exercise intervention on delaying the onset or slowing the progression of cognitive decline with different stages of Alzheimer's disease, (2) compares different types of exercise intervention on their role of cognitive function, (3) expounds the underlying mechanisms of exercise intervention on cognitive improvement, and (4) provides a structured strategy of exercise for clinical benefit.

\section{Type of Exercise Intervention}

The risk of developing AD increases exponentially with age, which affects daily life seriously and brings a heavy burden to each family. Therefore, there is an urgent demand to seek a therapy to at least ameliorate the progression of its cognitive disorder. Recently, exercise seems to be an emerging intervention as epidemiological and clinical studies suggest the positive effects of exercise training on cognition and counteracting the detrimental effects of neurocognitive illnesses. However, there is no consistent agreement of standard strategies for exercise intervention, and a better understanding of what type of exercise is most beneficial for cognitive performance is required especially.

2.1. Cognitive Exercise. There is some significant evidence to support claims of effectiveness of cognitive exercises including cognitive training (CT), cognitive stimulation (CS), and cognitive rehabilitation (CR) that differ in tasks. CT majors in standard tasks; extended cognitive practice training interventions have shown its role on enhancing performance in untrained cognitive tasks [17], and training resulted in improved targeted cognitive abilities (reasoning and speed) for 10 years [18]. A RCT illustrated that 10 sessions of occupational therapy improved functional capacity and helped AD patients adapt to their cognitive limitations through compensatory strategies [19]. However, the benefits of cognitive tasks cannot transfer flexibly and efficiently when accepters come to dissimilar tasks $[20,21]$. CS refers to a wider range of activities that lack standardization, which aimed for general improvement in cognitive functions like puzzles, word games, and indoor gardening [22], while CR centers on a settled goal such as reasoning exercises, which resulted in less functional descent in self-reported activities of daily living $[23,24]$. Nevertheless, opinions also divided into whether cognitive exercises induced only limited effects in executive function. Basak et al. found better performance in task switching, reasoning, working memory, and visual short-term memory after a real-time strategy video game, which indicates the enhancement of executive control process [25], while other team insists training older adults with nonaction video games enhances attention, immediate and delayed visual recognition memory, and processing speed except working memory (WM) and executive control [26].

2.2. Physical Training. More and more evidence from epidemiological, cross-sectional, and RCTs confirm that physical training such as aerobic [27-32] and resistance training [33-38] is associated with a reduced risk of cognitive decline. Aerobic exercises gain benefits by improving brain function mainly. In the early animal studies in 1995, Cotman and colleagues confirmed that a short-term wheel running for two days resulted in increased brain-derived neurotropic factor (BDNF) in the hippocampus and caudal cortex, which promotes the function of neurons [39]. Moreover, studies have demonstrated that aerobic exercises attenuate age-related myelin declines of corpus callosum [40] and remain white matter integrity [41] via better cardiorespiratory fitness. Higher levels of aerobic fitness alleviate hippocampal decay, increase hippocampal volume, and obtain better spatial memory performance as a consequence [29]. Those who participate in higher levels of physical exercises perform significantly better on global cognition and executive functioning [30-32]. On the other hand, resistance training works as an approach for cognitive enhancement as well. Twelve months of once or twice weekly resistance training benefited gait speed and decreased the risk for falls, which affects the daily life seriously [33]. However, different from aerobicbased exercise training, the mechanisms of resistance training focus on biomarkers which impact on neural functions such as insulin-like growth factor 1 (IGF-1) [34, 42] and serum homocysteine. Cassilhas et al. brought in sixty-two elderly individuals, let them participate in either moderateor high-intensity resistance training, and found that the levels of IGF-1 which promotes neuronal growth were higher than those of the control group [34]. To the contrary, homocysteine decreases after resistance exercise training and obtains positive results because of its negative effects on neural function in the elderly [43]. Meanwhile, the relationship between Tai Chi (one of the typical modes of resistance training) and cognition was carried out in many studies. Chang and Wayne's group have gained positive results $[35,36]$ while Snowden et al. showed limited evidence of cognitive benefits [44]. Furthermore, a series of exercise programme comprised of resistance and balance training exercises was tested in many studies. Brown and coworkers verified that a programme composed of group-based exercise improved cognitive ability of fluid intelligence significantly [37]. Home-based strength and balance retraining was confirmed effective in executive functioning by Liu-Ambrose et al. [38]. However, different meta-analyses and systemic reviews have controversial opinions about physical intervention. A meta-analysis in 2014 found no significant cognitive benefit of aerobic training [45], and a most recent systematic review in 2017 showed no or limited effects [16], while large and specific benefits were found in 2003 [46] for the impact of physical training on executive function. Diverse and precise ways of evaluation and standardized assessment of cognition improvement in recent years may be one of the important reasons for the distinction. 
2.3. Combine Training. The research on the combined effects of cognitive and physical exercises is rising; some research has reported that combining mental and physical exercises may be more effective than either alone and raised the point that cognitive decline is multicausal and onefold intervention will possibly remain insufficient [46, 47]. Exergaming is a typical type that combines physical exercise with interactive virtual reality, which provides cognitive stimulation when taking part in physical activities, for example, stationary cycling with virtual reality tours. Anderson-Hanley et al. confirmed that exergaming improved executive function and clinical status of mild cognitive impairment patients [15]. Meanwhile, Maillot et al. came to the similar conclusion that exergaming contributes to physical function and processing speed, which is the reflection of executive control capacity [48]. Simultaneous physical and cognitive exercises have greater potential for improving global cognition (working memory, episodic memory, and executive function) in a dose-response manner [49] and enhance frontal cognitive functions and gait [50] as well as neuroplasticity [15] while aerobic or resistance training has no advantage on episodic memory [51]. On the other hand, an interactive physical and cognitive exercise system (iPACES) uses neuroexergaming wherein older adults engage in a physical exercise pedaling and steering a stationary bike along a virtue bike path to achieve their target heart rate and play a computer game theoretically designed to train cognition. Neuro-exergaming gained positive results in neuropsychological effects and executive function compared with exergaming or neurogaming groups, suggesting that combined exercises work well than focusing on either alone [52]. In addition, exergaming gains better engagements because of its enjoyment as it is often a challenge to motivate elders adhere to long-term exercises. However, it should be noted that when cognitive and physical exercises take part separately rather than simultaneously or interactively, no significant benefit of combined training $[53,54]$ would be found compared with either alone. Meanwhile, the amount of activity is important at the same time; a RCT in JAMA examined the synergetic effects of combined physical and mental activities in the elderly. For participants engaged in home-based mental activity plus class-based physical activity for 12 weeks and randomized to different groups according to the type of exercise intervention (mental activity: intensive computer or educational DVDs; physical activity: aerobic or stretching and toning), results demonstrated that there was no significant difference across all 4 randomized groups, suggesting that the amount and intensity of exercise is more important than the type of activity [55].

\section{Other Influential Factors of Exercise Intervention}

In addition to the type of exercise, a large amount of variation exists in the effect of exercise on cognition benefits. The duration of exercise intervention and the sex of participants are two major factors that need to be considered. Long-term and regular training has proven to be effective to improve performance on cognitive tasks such as executive function
[56], long-term memory and attention [57], and has a positive impact on brain function via better cardiorespiratory fitness [40], increasing cerebral blood flow [58], and hippocampal volume [29]. However, even an acute, one-off exercise results in improvements on cognitive function. For example, participants who completed a 20-minute treadmill-based aerobic exercise for 5 days gained better cognitive control by flexible allocation of attention resources during the task [59]. Forty-eight subjects were allocated into a visuomotor accuracy-tracking task and drew the conclusion that acute exercise is related to long-term memory consolidation [60]. These findings are likely the results of the improvement of motor skill acquisition [61,62] and motor memory [60], the development of cortical environment which would be more optimal for plasticity [63], and the reduction of inhibition in the motor cortex [64] after a single session of activity period of exercise. On the other hand, in the early 2003, Colcombe and Kramer have shown that the gender of the study participants could affect the outcome of exercise-induced cognitive benefits. Female became one of the predictors for positive results [46]. Studies with higher percentage of women participants showed greater beneficial effects on executive functions and no or marginally significant difference on episodic memory, visuospatial functions, word fluency, and processing speed [51]. Six months of large amount of aerobic exercise had sexdifferent effects on cognition; women gained better performance on various tasks of executive function than men [56]. Those results may relate to gender differences in brainderived neurotrophic factor [51] and aerobic exerciseinduced hypothalamic-pituitary-adrenal axis $[51,56]$. In the meantime, many of the body diseases are also promoting factors of dementia especially the vascular dementia after cerebral infarction as those diseases compromised cognitive and brain health and consequently cause the risk of dementia. Therefore, preventing the happening of other chronic somatic diseases will also be one of the means to reduce the morbidity of dementia. Moreover, the relationship between exercises and diseases has got consistent results. Highintensity physical activities have been found to be faithfully associated with the reduction of all-cause mortality [65] and benefits in the secondary prevention of many chronic illness such as coronary heart disease, diabetes, and stroke. Meanwhile, the rehabilitation of diseases can also see the effect of exercise intervention [66]. Unfortunately, few individuals participate in aerobic or strengthening activities despite education from hospital and government. However, these studies identify exercise as a factor that reduces the risk of dying while its role in cognition has not been testified drastically.

\section{Exercise Efficacy to Improve Cognition with Different Stages of Alzheimer's Disease}

4.1. Mild Cognitive Impairment (MCI). Mild cognitive impairment (MCI) represents a transition stage of cognitive functioning between normal aging and dementia, which represents newly acquired cognitive deficits that are more severe than individuals with the same age and educational background [67] or emerge subjective concern regarding 
change in cognition while functional abilities in everyday life are preserved $[68,69]$. The cognitive dysfunctions including episodic and semantic memory [3, 14], working memory, and executive function [3] are discernible in MCI, and the initial symptom of MCI is a decline in memory (amnestic MCI) [67] such as familiar names [70]. Moreover, pathological changes such as amyloid plaques and agminated tau protein in regions of entorhinal cortex, parahippocampal gyrus, and subiculum in the medial temporal lobes can be tracked in MCI as well, although it may be not that severe compared with $\mathrm{AD}$ [71]. MCI patients have higher risk of developing $\mathrm{AD}, 40 \%$ of individuals diagnosed with $\mathrm{MCI}$ progressing to $\mathrm{AD}$ four years later [72]. However, there is a process for the transition from normal cognition to mild cognitive impairment and to Alzheimer's disease that with typical clinical symptoms. MCI patients could own normal cognitive functioning if with effective intervention while suffer rapid decline as the progression of the disease [73] and measures need to be taken at early stage as a result. Nevertheless, the thorniest problem is that there are yet no approved drug treatments to MCI. Cholinesterase inhibitors had a negligible effect in MCI [68] while Ginkgo biloba is ineffective in primary prevention [74]. Peterson et al. conducted a RCT that discusses vitamin $\mathrm{E}$ and donepezil in subjects with MCI. Vitamin E did not postpone the progression to Alzheimer's disease at any time node and proved to be invalid in patients with $\mathrm{MCI}$, and donepezil significantly retarded the course of Alzheimer's disease during the first 12 months of the treatment year, but the rate of progression to $\mathrm{AD}$ was not reduced after 3 years [74]. However, a large body of literature suggests that exercise intervention may decrease the risk of Alzheimer's disease for MCI. Studies indicate that computerized cognitive training alleviates the cognition decline during the MCI [15, 75-77]. Law et al. designed a RCT aimed at evaluating the effects of a series of functional tasks on their role in MCI; results showed that general cognitive functions, memory, executive function, and the ability of daily life improved both in postintervention and 6-month follow-up [75]. Computer-based cognitive rehabilitation (CBCR) was assessed with MCI by Galante and colleagues, suggesting that CBCR plays a role in putting off the continuous progression of cognitive decline to $\mathrm{AD}$ [77]. Anderson-Hanley et al. confirmed that exergaming improved executive function and clinical status of mild cognitive impairment patient [15]. In addition, other studies discuss the efficiency of exercise training in MCI and $\mathrm{AD}$ which show that the improvement in $\mathrm{AD}$ is weak and limited compared with patients of MCI [76, 78]. A 4-week cognitive multicomponent rehabilitation resulted in significant improvements on activities of daily life and episodic memory in patients with MCI and nonsignificant increase with AD patients [78].

4.2. Moderate to Severe Alzheimer's Disease. During the past decades, quite a lot of studies work on Alzheimer's disease, but no major breakthroughs seem to be forthcoming. So far, there have been no curative therapies for this terminal disease including traditional and emerging drugs as it is almost impossible to reverse the severe cognitive impairment and neurodegeneration. Cholinesterase inhibitors (donepezil, rivastigmine, and galantamine) and memantine are the major pharmacotherapy. RCTs and reviews have demonstrated cognitive benefits of drug treatments while there seems minor clinical significance. A long-term donepezil RCT in Lancet showed small but significant cognitive improvement in MMSE. However, no benefits were seen in institutionalization rates or progression of disability after 3 years [79]. Memantine is the only drug approved by the US Food and Drug Administration in 2003. Placebo-controlled, double-blind, parallel group, randomized trials of memantine in people with different stages of Alzheimer's disease were analyzed and found that memantine has a small but significant benefit effect in moderate to severe AD but those with MCI did not gain that improvement in cognition and thus provide a reasonable choice for moderate to severe $\mathrm{AD}$ [80]. Therefore, the treatment goal of $\mathrm{AD}$ has turned to delay the progression of cognition decline and maintain the ability of daily life. Research on nondrug therapies has produced promising cost-effective strategies for dementia [81, 82], which improve behavior, mood, and the quality of life for families of patients with AD [82].

Meta-analysis aimed at comparing the effect of drug treatment and exercise intervention in $\mathrm{AD}$, indicating that pharmacological therapy has inflexible impact on cognitive function while exercise has the potential to modify cognition dysfunction in AD as well [2]. Some experiments have established that exercise intervention of dementia is invalid especially in cognitive function [86] and behavioral disturbance [83]. However, cognition will decline rapidly if one is without exercise. A RCT in JAMA suggested that the physical function deteriorated during the year after exercise intervention regardless of group-based exercise or tailored homebased exercise while those receiving usual medicine care merely have a significantly faster decline [81]. Nascimento et al. obtained similar results that the experimental group showed a tendency for less reduction in neuropsychic disturbance and performance of instrumental activities compared to the control group who lacks exercise [84].

Meanwhile, intensive and long-term exercises were proven useful to physical functioning of home-dwelling [81] and institutionalized patients with $\mathrm{AD}$ [83], leading to relative better activities of daily life [83]. In addition, as dementia progresses, the weight loss, sarcopenia [81], and the decline in frontal cognitive functions [85] become more severe, connecting with a significant risk of falls, which is one of the important elements that result in disability, permanent institutional care, and mortality. Fortunately, multimodal exercise intervention has been identified effective in the improvement of frontal cognitive functions [50,86] and proved to be an irreplaceable part of the rehabilitation to $\mathrm{AD}$ patients despite their severe cognitive impairment [87]. On the other hand, some studies take exercise as part of comprehensive intervention while results were controversial. Teri et al. suggested that exercise training plus behavioral management help improve physical function for patients with Alzheimer disease [88]. However, two years of homebased occupational therapy plus collaborative care did not obtain definite consequence on improving the rate of functional decline in patients with $\mathrm{AD}$ [42]. 
4.3. Normal Aging People. Along with the aging of the population and the expectation of the elderly to be physically and psychologically healthy, there is an imperative need to take effective interventions to improve or at least maintain cognitive function in normal aging people. Here, the normal cognitive decline associated with age which is different from MCI (beyond normally excepted cognitive decline) and dementia (cognitive decline in one of several cognitive domains) is discussed. A 6-week double-blind randomized placebo-controlled trail did not obtain positive results in semantic encoding by donepezil with cognitively normal elderly [89]. Other RCT on memantine showed no benefits on memory with age-associated memory impairment similarly [90]. Meanwhile, pharmacological interventions such as hormonal therapies, Ginkgo, and vitamins have not gain enough evidence for cognition prevention [91-94] as well. However, a large number of experiments have established the impact of nonpharmacological interventions on cognition. Cognitive training $[23,34,95,96]$ may acquire consistent memory benefit while physical exercise improves cognitive performance [37, 57, 97]. High-quality research suggested that cognitive training in cognitively normal elderly can be effective and durable. In this study, the neuropsychological gain was encouraging; the training effects were equivalent to a protection that the elders will not suffer from cognitive decline for 7 to 14 years [98]. Evidence above suggests that exercise intervention plays an important and irreplaceable role on the prevention of cognitive deterioration with healthy older people.

\section{The Underlying Mechanisms of Exercise Intervention on Cognitive Improvement}

Emerging evidence has indicated that exercise intervention does benefit to cognitive function, but the underlying molecular mechanisms remain unknown. Currently, AD is diagnosed through insoluble amyloid $\beta$-peptide $(\mathrm{A} \beta)$ in extracellular plaques and agminated tau protein in the intracellular neurofibrillary tangles by the detection of postmortem [3, 4]. As a result, it is crucial to clarify how exercise affects AD pathology. Studies of pathological change in transgenic AD mouse and structural imaging in human have provided some clues. Adlard and colleagues found that voluntary exercise reduced $A \beta$ load in frontal cortex and hippocampus in transgenic $\mathrm{AD}$ mouse and the mechanism proved to be independent of classical $A \beta$ degradation pathways for there was no change in the expression of the key enzyme neprilysin and insulindegrading enzyme (IDE) [10]. However, short-term exercise activity decreased the proteolytic fragments of amyloid precursor protein (APP), supporting that exercise reduced $\mathrm{A} \beta$ by regulating the APP metabolism and the amyloid cascade, leading to the final result of learning and memory improvement [10]. On the other hand, the examination of the effects of environmental enrichment (large cages containing running wheel, colorful tunnels, and assorted toys) in transgenic $\mathrm{AD}$ mouse models showed controversial consequences in terms of amyloid deposition, with reduced
$\mathrm{A} \beta$ levels and amyloid deposition in some investigations $[11,99]$ but neither decrease of amyloid or tau by studies of others $[100,101]$. Therefore, exercise-induced cognitive improvement with no change on the level of $A \beta$ may be associated with the mechanism independent of $A \beta$ deposition. Moreover, other studies use radiological technology and serum biochemical markers to clarify the interaction between exercise and $\mathrm{AD}$ pathology in humans. Liang's group chose Pittsburgh compound B (PiB) detected through positron emission tomography (PET), and $\mathrm{A} \beta$ and hyperphosphorylated tau proteins (ptau) measured in cerebrospinal fluid (CSF) as biomarkers, and found that exercise was associated with reduced amyloid deposition and no significant changes in ptau [102]. This may be due to the participant of the research whom was in the early stage of cognitive decline while ptau is largely formed in the later course of $\mathrm{AD}$ [103]. Similar to animal studies, there are divergent results in the relationship between exercise and human $\mathrm{AD}$ biomarkers as well. Gidicsin's group confirmed that lifelong cognitive activity gives rise to cognitive improvement by a mechanism that is independent of $\mathrm{A} \beta$ deposition for there was no difference in the PiB retention [104].

In addition, it is important to note that exerciseinduced modulation of ROS plays a role in better cognitive function and increased neurogenesis. As the central nervous system is too sensitive to the abnormal oxidative stress, studies confirmed that markers of lipid peroxidation are elevated in $\mathrm{AD}$ and $\mathrm{MCI}$ [9]. At the same time, studies have shown that the activities of antioxidant enzymes superoxide dismutase (SOD) and glutathione peroxidase (GPX) were increased in stem and corpus striatum after exercise [9]. It was also observed that the activity of neprilysin was increased, leading to the degradation of $\mathrm{A} \beta$ which may be responsible for the improvement of memory and cognition [11]. However, low levels of ROS may also impair cell function and break redox homeostasis while exercise results in the balance of oxidative challenge [105]. On the other hand, exercise is an important modulator of neurotrophins including BDNF, IGF-1, and vascular endothelial growth factor (VEGF). It has been suggested that BDNF is extremely critical in synaptic plasticity, neuroplasticity, and the development of learning and memory [106]. Not surprisingly, studies confirmed that the expression of BDNF could be upregulated by exercise and the downstream signaling pathway could also be regulated by exercise [13]. Other major neurotrophins elevated by exercise are IGF-1 and VEGF, which are critical for nerve growth and nutrition supply to the brain $[13,107]$. Exercise-induced reduction of inflammatory markers (CRP, TNF- $\alpha$, and IL-6) is probably one of its molecular mechanisms as well [108]. Furthermore, because cholinergic neuron damage is one of the causes of $\mathrm{AD}$, the role of exercise in modulating cholinergic system also needs to be paid attention on. Results from some studies suggested that exercise may increase the level of acetylcholine [109] and the receptor density of dopamine and muscarinic [12], regulate neurotransmitter release in the hippocampus [110], and promote neuron proliferation [106]. 
TABLE 1: Exercise management of Alzheimer's disease.

\begin{tabular}{|c|c|c|}
\hline Type of exercise intervention & Stages of AD & Evidence \\
\hline $\begin{array}{l}\text { Cognitive exercise } \\
\text { Cognitive training } \\
\text { Cognitive stimulation } \\
\text { Cognitive rehabilitation }\end{array}$ & Mild/moderate & $\begin{array}{c}\text { Improve cognition } \\
\text { Improve targeted cognitive abilities } \\
\text { Improve self-reported instrumental abilities of daily living }\end{array}$ \\
\hline $\begin{array}{l}\text { Physical training } \\
\text { Aerobic training } \\
\text { Resistance training }\end{array}$ & Mild/moderate/severe & $\begin{array}{l}\text { Improve physical function } \\
\text { Improve executive function } \\
\text { Improve spatial memory performance }\end{array}$ \\
\hline $\begin{array}{l}\text { Combine training } \\
\text { Consecutive physical and cognitive exercise } \\
\text { Simultaneous physical and cognitive exercise } \\
\text { Interactive physical and cognitive exercise }\end{array}$ & Mild/moderate & $\begin{array}{l}\text { Improve physical function } \\
\text { Improve executive control capacity } \\
\text { Improve global cognition } \\
\text { Improve clinical status }\end{array}$ \\
\hline
\end{tabular}

\section{Summary and Conclusion}

Overall, exercise intervention is a promising, cost-effective treatment that benefits cognitive function and plays an important role on preventing the progression to dementia with mild cognitive impairment and older adults at risk of dementia. On the other hand, for patients with Alzheimer's disease, exercise intervention could slow down the rapid cognitive impairment and be part of comprehensive treatments. We summarized the exercise management of Alzheimer's disease (Table 1). However, to date, no standard strategy gets consistent agreement to different stages of cognitive decline. Though we have compared different types of exercise intervention, the duration of training sessions and the gender of the study participants in this review, no definite approach was gain still. Even if we have paid extensive attention to the mechanisms of exercise to cognitive improvement, including enhancing brain function, increasing cerebral blood, regulation of molecular biomarkers, balancing the oxidative challenge, reducing $\mathrm{A} \beta$ load and the levels of hyperphosphorylated tau proteins, and modulating cholinergic system, the detailed mechanisms of neural plasticity in dementia still require further tests to confirm. More experiments are needed to break through the treatment bottleneck of Alzheimer's disease.

\section{Conflicts of Interest}

The authors confirm no conflicts of interest regarding the publication of this article.

\section{Acknowledgments}

This work was supported by grants from the Natural Science Foundation of China (NSFC) (nos. 31471120, 31540076, and 31171123) and Jilin Science and Technology Agency funding (20180519003JH).

\section{References}

[1] S. L. Murphy, J. Xu, and K. D. Kochanek, "Deaths: final data for 2010," National Vital Statistics Report, vol. 61, no. 4, pp. 1-117, 2013.
[2] M. Wortmann, "Dementia: a global health priority - highlights from an ADI and World Health Organization report," Alzheimer's Research \& Therapy, vol. 4, no. 5, p. 40, 2012.

[3] A. M. Kirova, R. B. Bays, and S. Lagalwar, "Working memory and executive function decline across normal aging, mild cognitive impairment, and Alzheimer's disease," BioMed Research International, vol. 2015, Article ID 748212, 9 pages, 2015.

[4] S. D. Skaper, L. Facci, M. Zusso, and P. Giusti, "Synaptic plasticity, dementia and Alzheimer disease," CNS \& Neurological Disorders Drug Targets, vol. 16, no. 3, pp. 220-233, 2017.

[5] S. G. Di Santo, F. Prinelli, F. Adorni, C. Caltagirone, and M. Musicco, "A meta-analysis of the efficacy of donepezil, rivastigmine, galantamine, and memantine in relation to severity of Alzheimer's disease," Journal of Alzheimer's Disease, vol. 35, no. 2, pp. 349-361, 2013.

[6] J. S. Lin, E. O'Connor, R. C. Rossom, L. A. Perdue, and E. Eckstrom, "Screening for cognitive impairment in older adults: a systematic review for the U.S. Preventive Services Task Force," Annals of Internal Medicine, vol. 159, no. 9, pp. 601-612, 2013.

[7] L. S. Nagamatsu, T. C. Handy, C. L. Hsu, M. Voss, and T. Liu-Ambrose, "Resistance training promotes cognitive and functional brain plasticity in seniors with probable mild cognitive impairment," Archives of Internal Medicine, vol. 172, no. 8, pp. 666-668, 2012.

[8] H. Guiney, S. J. Lucas, J. D. Cotter, and L. Machado, "Evidence cerebral blood-flow regulation mediates exercisecognition links in healthy young adults," Neuropsychology, vol. 29, no. 1, pp. 1-9, 2015.

[9] M. Schrag, C. Mueller, M. Zabel et al., "Oxidative stress in blood in Alzheimer's disease and mild cognitive impairment: a meta-analysis," Neurobiology of Disease, vol. 59, pp. 100-110, 2013.

[10] P. A. Adlard, V. M. Perreau, V. Pop, and C. W. Cotman, "Voluntary exercise decreases amyloid load in a transgenic model of Alzheimer's disease," The Journal of Neuroscience, vol. 25, no. 17, pp. 4217-4221, 2005.

[11] O. Lazarov, J. Robinson, Y. P. Tang et al., "Environmental enrichment reduces $\mathrm{A} \beta$ levels and amyloid deposition in transgenic mice," Cell, vol. 120, no. 5, pp. 701-713, 2005.

[12] P. G. MacRae, W. W. Spirduso, T. J. Walters, R. P. Farrar, and R. E. Wilcox, "Endurance training effects on striatal D2 dopamine receptor binding and striatal dopamine metabolites in presenescent older rats," Psychopharmacology, vol. 92, no. 2, pp. 236-240, 1987. 
[13] M. P. Mattson, S. Maudsley, and B. Martin, "A neural signaling triumvirate that influences ageing and age-related disease: insulin/IGF-1, BDNF and serotonin," Ageing Research Reviews, vol. 3, no. 4, pp. 445-464, 2004.

[14] J. C. Smith, K. A. Nielson, P. Antuono et al., "Semantic memory functional MRI and cognitive function after exercise intervention in mild cognitive impairment," Journal of Alzheimer's Disease, vol. 37, no. 1, pp. 197-215, 2013.

[15] C. Anderson-Hanley, P. J. Arciero, A. M. Brickman et al., "Exergaming and older adult cognition: a cluster randomized clinical trial," American Journal of Preventive Medicine, vol. 42, no. 2, pp. 109-119, 2012.

[16] G. G. de Assis and K. M. de Almondes, "Exercise-dependent BDNF as a modulatory factor for the executive processing of individuals in course of cognitive decline. A systematic review," Frontiers in Psychology, vol. 8, p. 584, 2017.

[17] S. B. Hindin and E. M. Zelinski, "Extended practice and aerobic exercise interventions benefit untrained cognitive outcomes in older adults: a meta-analysis," Journal of the American Geriatrics Society, vol. 60, no. 1, pp. 136-141, 2012.

[18] G. W. Rebok, K. Ball, L. T. Guey et al., "Ten-year effects of the advanced cognitive training for independent and vital elderly cognitive training trial on cognition and everyday functioning in older adults," Journal of the American Geriatrics Society, vol. 62, no. 1, pp. 16-24, 2014.

[19] M. J. Graff, M. J. Vernooij-Dassen, M. Thijssen, J. Dekker, W. H. Hoefnagels, and M. G. Rikkert, "Community based occupational therapy for patients with dementia and their care givers: randomised controlled trial," $B M J$, vol. 333, no. 7580, p. 1196, 2006.

[20] A. M. Owen, A. Hampshire, J. A. Grahn et al., "Putting brain training to the test," Nature, vol. 465, no. 7299, pp. 775-778, 2010.

[21] T. L. Harrison, Z. Shipstead, K. L. Hicks, D. Z. Hambrick, T. S. Redick, and R. W. Engle, "Working memory training may increase working memory capacity but not fluid intelligence," Psychological Science, vol. 24, no. 12, pp. 2409-2419, 2013.

[22] T. Epperly, M. A. Dunay, and J. L. Boice, "Alzheimer disease: pharmacologic and nonpharmacologic therapies for cognitive and functional symptoms," American Family Physician, vol. 95, no. 12, pp. 771-778, 2017.

[23] S. L. Willis, S. L. Tennstedt, M. Marsiske et al., "Long-term effects of cognitive training on everyday functional outcomes in older adults," JAMA, vol. 296, no. 23, pp. 2805-2814, 2006.

[24] L. Clare and R. T. Woods, "Cognitive rehabilitation and cognitive training for early-stage Alzheimer's disease and vascular dementia," Cochrane Database of Systematic Reviews, no. 4, article CD003260, 2003.

[25] C. Basak, W. R. Boot, M. W. Voss, and A. F. Kramer, "Can training in a real-time strategy video game attenuate cognitive decline in older adults," Psychology and Aging, vol. 23, no. 4, pp. 765-777, 2008.

[26] S. Ballesteros, A. Prieto, J. Mayas et al., "Brain training with non-action video games enhances aspects of cognition in older adults: a randomized controlled trial," Frontiers in Aging Neuroscience, vol. 6, p. 277, 2014.

[27] L. E. Middleton, D. E. Barnes, L. Y. Lui, and K. Yaffe, "Physical activity over the life course and its association with cognitive performance and impairment in old age,"
Journal of the American Geriatrics Society, vol. 58, no. 7, pp. 1322-1326, 2010.

[28] H. Guiney and L. Machado, "Benefits of regular aerobic exercise for executive functioning in healthy populations," Psychonomic Bulletin \& Review, vol. 20, no. 1, pp. 73-86, 2013.

[29] K. I. Erickson, R. S. Prakash, M. W. Voss et al., "Aerobic fitness is associated with hippocampal volume in elderly humans," Hippocampus, vol. 19, no. 10, pp. 1030-1039, 2009.

[30] D. E. Barnes, T. Blackwell, K. L. Stone, S. E. Goldman, T. Hillier, and K. Yaffe, "Cognition in older women: the importance of daytime movement," Journal of the American Geriatrics Society, vol. 56, no. 9, pp. 1658-1664, 2008.

[31] B. M. Brown, J. J. Peiffer, H. R. Sohrabi et al., "Intense physical activity is associated with cognitive performance in the elderly," Translational Psychiatry, vol. 2, no. 11, article e191, 2012.

[32] F. Sofi, D. Valecchi, D. Bacci et al., "Physical activity and risk of cognitive decline: a meta-analysis of prospective studies," Journal of Internal Medicine, vol. 269, no. 1, pp. 107-117, 2011.

[33] T. Liu-Ambrose, L. S. Nagamatsu, P. Graf, B. L. Beattie, M. C. Ashe, and T. C. Handy, "Resistance training and executive functions: a 12-month randomized controlled trial," Archives of Internal Medicine, vol. 170, no. 2, pp. 170-178, 2010.

[34] R. C. Cassilhas, V. A. Viana, V. Grassmann et al., "The impact of resistance exercise on the cognitive function of the elderly," Medicine \& Science in Sports \& Exercise, vol. 39, no. 8, pp. 1401-1407, 2007.

[35] Y. K. Chang, Y. H. Nien, C. L. Tsai, and J. L. Etnier, "Physical activity and cognition in older adults: the potential of Tai Chi Chuan," Journal of Aging and Physical Activity, vol. 18, no. 4, pp. 451-472, 2010.

[36] P. M. Wayne, B. J. Gow, M. D. Costa et al., "Complexitybased measures inform effects of Tai Chi training on standing postural control: cross-sectional and randomized trial studies," PLoS One, vol. 9, no. 12, article e114731, 2014.

[37] A. K. Brown, T. Liu-Ambrose, R. Tate, and S. R. Lord, "The effect of group-based exercise on cognitive performance and mood in seniors residing in intermediate care and self-care retirement facilities: a randomised controlled trial," British Journal of Sports Medicine, vol. 43, no. 8, pp. 608-614, 2009.

[38] T. Liu-Ambrose, M. G. Donaldson, Y. Ahamed et al., "Otago home-based strength and balance retraining improves executive functioning in older fallers: a randomized controlled trial," Journal of the American Geriatrics Society, vol. 56, no. 10, pp. 1821-1830, 2008.

[39] S. A. Neeper, F. Gómez-Pinilla, J. Choi, and C. Cotman, "Exercise and brain neurotrophins," Nature, vol. 373, no. 6510, p. 109, 1995.

[40] N. F. Johnson, C. Kim, J. L. Clasey, A. Bailey, and B. T. Gold, "Cardiorespiratory fitness is positively correlated with cerebral white matter integrity in healthy seniors," NeuroImage, vol. 59, no. 2, pp. 1514-1523, 2012.

[41] Q. Tian, E. M. Simonsick, K. I. Erickson et al., "Cardiorespiratory fitness and brain diffusion tensor imaging in adults over 80 years of age," Brain Research, vol. 1588, pp. 63-72, 2014.

[42] S. E. Borst, D. V. De Hoyos, L. Garzarella et al., "Effects of resistance training on insulin-like growth factor-I and IGF binding proteins," Medicine and Science in Sports and Exercise, vol. 33, no. 4, pp. 648-653, 2001. 
[43] K. R. Vincent, R. W. Braith, T. Bottiglieri, H. K. Vincent, and D. T. Lowenthal, "Homocysteine and lipoprotein levels following resistance training in older adults," Preventive Cardiology, vol. 6, no. 4, pp. 197-203, 2003.

[44] M. Snowden, L. Steinman, K. Mochan et al., "Effect of exercise on cognitive performance in community-dwelling older adults: review of intervention trials and recommendations for public health practice and research," Journal of the American Geriatrics Society, vol. 59, no. 4, pp. 704-716, 2011.

[45] M. E. Kelly, D. Loughrey, B. A. Lawlor, I. H. Robertson, C. Walsh, and S. Brennan, "The impact of exercise on the cognitive functioning of healthy older adults: a systematic review and meta-analysis," Ageing Research Reviews, vol. 16, pp. 12-31, 2014.

[46] S. Colcombe and A. F. Kramer, "Fitness effects on the cognitive function of older adults: a meta-analytic study," Psychological Science, vol. 14, no. 2, pp. 125-130, 2003.

[47] W. D. Oswald, T. Gunzelmann, R. Rupprecht, and B. Hagen, "Differential effects of single versus combined cognitive and physical training with older adults: the SimA study in a 5year perspective," European Journal of Ageing, vol. 3, no. 4, pp. 179-192, 2006.

[48] P. Maillot, A. Perrot, and A. Hartley, "Effects of interactive physical-activity video-game training on physical and cognitive function in older adults," Psychology and Aging, vol. 27, no. 3, pp. 589-600, 2012.

[49] P. D. Bamidis, P. Fissler, S. G. Papageorgiou et al., "Gains in cognition through combined cognitive and physical training: the role of training dosage and severity of neurocognitive disorder," Frontiers in Aging Neuroscience, vol. 7, p. 152, 2015.

[50] F. G. Coelho, L. P. Andrade, R. V. Pedroso et al., "Multimodal exercise intervention improves frontal cognitive functions and gait in Alzheimer's disease: a controlled trial," Geriatrics \& Gerontology International, vol. 13, no. 1, pp. 198-203, 2013.

[51] C. K. Barha, J. C. Davis, R. S. Falck, L. S. Nagamatsu, and T. Liu-Ambrose, "Sex differences in exercise efficacy to improve cognition: a systematic review and meta-analysis of randomized controlled trials in older humans," Frontiers in Neuroendocrinology, vol. 46, pp. 71-85, 2017.

[52] C. Anderson-Hanley, M. Maloney, N. Barcelos, K. Striegnitz, and A. Kramer, "Neuropsychological benefits of neuroexergaming for older adults: a pilot study of an interactive physical and cognitive exercise system (iPACES)," Journal of Aging and Physical Activity, vol. 25, no. 1, pp. 73-83, 2017.

[53] K. Linde and D. Alfermann, "Single versus combined cognitive and physical activity effects on fluid cognitive abilities of healthy older adults: a 4-month randomized controlled trial with follow-up," Journal of Aging and Physical Activity, vol. 22, no. 3, pp. 302-313, 2014.

[54] J. Rahe, A. Petrelli, S. Kaesberg, G. R. Fink, J. Kessler, and E. Kalbe, "Effects of cognitive training with additional physical activity compared to pure cognitive training in healthy older adults," Clinical Interventions in Aging, vol. 10, pp. 297-310, 2015.

[55] D. E. Barnes, W. Santos-Modesitt, G. Poelke et al., "The Mental Activity and eXercise (MAX) trial: a randomized controlled trial to enhance cognitive function in older adults," JAMA Internal Medicine, vol. 173, no. 9, pp. 797-804, 2013.

[56] L. D. Baker, L. L. Frank, K. Foster-Schubert et al., "Effects of aerobic exercise on mild cognitive impairment: a controlled trial," Archives of Neurology, vol. 67, no. 1, pp. 71-79, 2010.
[57] P. J. Smith, J. A. Blumenthal, B. M. Hoffman et al., "Aerobic exercise and neurocognitive performance: a meta-analytic review of randomized controlled trials," Psychosomatic Medicine, vol. 72, no. 3, pp. 239-252, 2010.

[58] A. C. Pereira, D. E. Huddleston, A. M. Brickman et al., "An in vivo correlate of exercise-induced neurogenesis in the adult dentate gyrus," Proceedings of the National Academy of Sciences of the United States of America, vol. 104, no. 13, pp. 5638-5643, 2007.

[59] K. C. O’Leary, M. B. Pontifex, M. R. Scudder, M. L. Brown, and C. H. Hillman, "The effects of single bouts of aerobic exercise, exergaming, and videogame play on cognitive control," Clinical Neurophysiology, vol. 122, no. 8, pp. 1518-1525, 2011.

[60] M. Roig, K. Skriver, J. Lundbye-Jensen, B. Kiens, and J. B. Nielsen, "A single bout of exercise improves motor memory," PLoS One, vol. 7, no. 9, article e44594, 2012.

[61] M. A. Statton, M. Encarnacion, P. Celnik, and A. J. Bastian, "A single bout of moderate aerobic exercise improves motor skill acquisition," PLoS One, vol. 10, no. 10, article e0141393, 2015.

[62] C. S. Mang, N. J. Snow, K. L. Campbell, C. J. Ross, and L. A. Boyd, "A single bout of high-intensity aerobic exercise facilitates response to paired associative stimulation and promotes sequence-specific implicit motor learning," Journal of Applied Physiology, vol. 117, no. 11, pp. 1325-1336, 2014.

[63] A. E. Smith, M. R. Goldsworthy, T. Garside, F. M. Wood, and M. C. Ridding, "The influence of a single bout of aerobic exercise on short-interval intracortical excitability," Experimental Brain Research, vol. 232, no. 6, pp. 1875-1882, 2014.

[64] T. Lulic, J. El-Sayes, H. J. Fassett, and A. J. Nelson, "Physical activity levels determine exercise-induced changes in brain excitability," PLoS One, vol. 12, no. 3, article e0173672, 2017.

[65] P. T. Katzmarzyk, I. Janssen, and C. I. Ardern, "Physical inactivity, excess adiposity and premature mortality," Obesity Reviews, vol. 4, no. 4, pp. 257-290, 2003.

[66] H. Naci and J. P. Ioannidis, "Comparative effectiveness of exercise and drug interventions on mortality outcomes: metaepidemiological study," British Journal of Sports Medicine, vol. 49, no. 21, pp. 1414-1422, 2015.

[67] C. Andrade and R. Radhakrishnan, "The prevention and treatment of cognitive decline and dementia: an overview of recent research on experimental treatments," Indian Journal of Psychiatry, vol. 51, no. 1, pp. 12-25, 2009.

[68] A. Ströhle, D. K. Schmidt, F. Schultz et al., "Drug and exercise treatment of Alzheimer disease and mild cognitive impairment: a systematic review and meta-analysis of effects on cognition in randomized controlled trials," The American Journal of Geriatric Psychiatry, vol. 23, no. 12, pp. 1234-1249, 2015.

[69] M. S. Albert, S. T. DeKosky, D. Dickson et al., "The diagnosis of mild cognitive impairment due to Alzheimer's disease: recommendations from the National Institute on AgingAlzheimer's Association workgroups on diagnostic guidelines for Alzheimer's disease," Alzheimer's \& Dementia, vol. 7, no. 3, pp. 270-279, 2011.

[70] C. Jonker, M. I. Geerlings, and B. Schmand, "Are memory complaints predictive for dementia? A review of clinical and population-based studies," International Journal of Geriatric Psychiatry, vol. 15, no. 11, pp. 983-991, 2000. 
[71] J. Attems and K. A. Jellinger, "Olfactory tau pathology in Alzheimer disease and mild cognitive impairment," Clinical Neuropathology, vol. 25, no. 6, pp. 265-271, 2006.

[72] R. C. Petersen, "Mild cognitive impairment: transition between aging and Alzheimer's disease," Neurología, vol. 15, no. 3, pp. 93-101, 2000.

[73] A. Muscari, C. Giannoni, L. Pierpaoli et al., "Chronic endurance exercise training prevents aging-related cognitive decline in healthy older adults: a randomized controlled trial," International Journal of Geriatric Psychiatry, vol. 25, no. 10, pp. 1055-1064, 2010.

[74] R. C. Petersen, R. G. Thomas, M. Grundman et al., "Vitamin $\mathrm{E}$ and donepezil for the treatment of mild cognitive impairment," The New England Journal of Medicine, vol. 352, no. 23, pp. 2379-2388, 2005.

[75] L. L. Law, F. Barnett, M. K. Yau, and M. A. Gray, "Effects of functional tasks exercise on older adults with cognitive impairment at risk of Alzheimer's disease: a randomised controlled trial," Age and Ageing, vol. 43, no. 6, pp. 813-820, 2014.

[76] N. T. Hill, L. Mowszowski, S. L. Naismith, V. L. Chadwick, M. Valenzuela, and A. Lampit, "Computerized cognitive training in older adults with mild cognitive impairment or dementia: a systematic review and meta-analysis," The American Journal of Psychiatry, vol. 174, no. 4, pp. 329-340, 2017.

[77] E. Galante, G. Venturini, and C. Fiaccadori, "Computerbased cognitive intervention for dementia: preliminary results of a randomized clinical trial," Giornale italiano di medicina del lavoro ed ergonomia, vol. 29, no. 3, Supplement B, pp. B26-B32, 2007.

[78] A. Kurz, C. Pohl, M. Ramsenthaler, and C. Sorg, "Cognitive rehabilitation in patients with mild cognitive impairment," International Journal of Geriatric Psychiatry, vol. 24, no. 2, pp. 163-168, 2009.

[79] C. Courtney, D. Farrell, R. Gray et al., "Long-term donepezil treatment in 565 patients with Alzheimer's disease (AD2000): randomised double-blind trial," Lancet, vol. 363, no. 9427, pp. 2105-2115, 2004.

[80] G. K. Wilcock, "Memantine for the treatment of dementia," The Lancet Neurology, vol. 2, no. 8, pp. 503-505, 2003.

[81] K. H. Pitkälä, M. M. Pöysti, M. L. Laakkonen et al., "Effects of the Finnish Alzheimer disease exercise trial (FINALEX): a randomized controlled trial," JAMA Internal Medicine, vol. 173, no. 10, pp. 894-901, 2013.

[82] J. Olazarán, B. Reisberg, L. Clare et al., "Nonpharmacological therapies in Alzheimer's disease: a systematic review of efficacy," Dementia and Geriatric Cognitive Disorders, vol. 30, no. 2, pp. 161-178, 2010.

[83] Y. Rolland, F. Pillard, A. Klapouszczak et al., "Exercise program for nursing home residents with Alzheimer's disease: a 1-year randomized, controlled trial," Journal of the American Geriatrics Society, vol. 55, no. 2, pp. 158-165, 2007.

[84] C. M. Nascimento, C. V. Teixeira, L. T. Gobbi, S. Gobbi, and F. Stella, "A controlled clinical trial on the effects of exercise on neuropsychiatric disorders and instrumental activities in women with Alzheimer's disease," Brazilian Journal of Physical Therapy, vol. 16, no. 3, pp. 197-204, 2012.

[85] F. G. Coelho, F. Stella, L. P. de Andrade et al., "Gait and risk of falls associated with frontal cognitive functions at different stages of Alzheimer's disease," Aging, Neuropsychology and Cognition, vol. 19, no. 5, pp. 644-656, 2012.
[86] L. P. de Andrade, L. T. Gobbi, F. G. Coelho, G. Christofoletti, J. L. Costa, and F. Stella, "Benefits of multimodal exercise intervention for postural control and frontal cognitive functions in individuals with Alzheimer's disease: a controlled trial," Journal of the American Geriatrics Society, vol. 61, no. 11, pp. 1919-1926, 2013.

[87] L. Poynter, J. Kwan, A. A. Sayer, and M. Vassallo, "Does cognitive impairment affect rehabilitation outcome," Journal of the American Geriatrics Society, vol. 59, no. 11, pp. 2108-2111, 2011.

[88] L. Teri, L. E. Gibbons, S. M. McCurry et al., "Exercise plus behavioral management in patients with Alzheimer disease: a randomized controlled trial," JAMA, vol. 290, no. 15, pp. 2015-2022, 2003.

[89] D. B. FitzGerald, G. P. Crucian, J. B. Mielke et al., "Effects of donepezil on verbal memory after semantic processing in healthy older adults," Cognitive and Behavioral Neurology, vol. 21, no. 2, pp. 57-64, 2008.

[90] S. Ferris, L. Schneider, M. Farmer, G. Kay, and T. Crook, “A double-blind, placebo-controlled trial of memantine in ageassociated memory impairment (memantine in AAMI)," International Journal of Geriatric Psychiatry, vol. 22, no. 5, pp. 448-455, 2007.

[91] O. P. Almeida, N. T. Lautenschlager, S. Vasikaran, P. Leedman, A. Gelavis, and L. Flicker, "A 20-week randomized controlled trial of estradiol replacement therapy for women aged 70 years and older: effect on mood, cognition and quality of life," Neurobiology of Aging, vol. 27, no. 1, pp. 141-149, 2006.

[92] M. M. Cherrier, A. M. Matsumoto, J. K. Amory et al., "The role of aromatization in testosterone supplementation: effects on cognition in older men," Neurology, vol. 64, no. 2, pp. 290-296, 2005.

[93] P. R. Solomon, F. Adams, A. Silver, J. Zimmer, and R. DeVeaux, "Ginkgo for memory enhancement: a randomized controlled trial," JAMA, vol. 288, no. 7, pp. 835-840, 2002.

[94] J. H. Kang, N. Cook, J. Manson, J. E. Buring, and F. Grodstein, "A randomized trial of vitamin E supplementation and cognitive function in women," Archives of Internal Medicine, vol. 166, no. 22, pp. 2462-2468, 2006.

[95] A. S. Berry, T. P. Zanto, W. C. Clapp et al., "The influence of perceptual training on working memory in older adults," PLoS One, vol. 5, no. 7, article e11537, 2010.

[96] G. E. Smith, P. Housen, K. Yaffe et al., “A cognitive training program based on principles of brain plasticity: results from the Improvement in Memory with Plasticity-based Adaptive Cognitive Training (IMPACT) study," Journal of the American Geriatrics Society, vol. 57, no. 4, pp. 594-603, 2009.

[97] L. D. Baker, L. L. Frank, K. Foster-Schubert et al., "Aerobic exercise improves cognition for older adults with glucose intolerance, a risk factor for Alzheimer's disease," Journal of Alzheimer's disease: JAD, vol. 22, no. 2, pp. 569-579, 2010.

[98] K. Ball, D. B. Berch, K. F. Helmers et al., "Effects of cognitive training interventions with older adults: a randomized controlled trial," JAMA, vol. 288, no. 18, pp. 2271-2281, 2002.

[99] N. Berardi, C. Braschi, S. Capsoni, A. Cattaneo, and L. Maffei, "Environmental enrichment delays the onset of memory deficits and reduces neuropathological hallmarks in a mouse model of Alzheimer-like neurodegeneration," Journal of Alzheimer's Disease, vol. 11, no. 3, pp. 359-370, 2007. 
[100] G. W. Arendash, M. F. Garcia, D. A. Costa, J. R. Cracchiolo, I. M. Wefes, and H. Potter, "Environmental enrichment improves cognition in aged Alzheimer's transgenic mice despite stable $\beta$-amyloid deposition," Neuroreport, vol. 15, no. 11, pp. 1751-1754, 2004.

[101] S. A. Wolf, G. Kronenberg, K. Lehmann et al., "Cognitive and physical activity differently modulate disease progression in the amyloid precursor protein (APP)-23 model of Alzheimer's disease," Biological Psychiatry, vol. 60, no. 12, pp. 1314-1323, 2006.

[102] K. Y. Liang, M. A. Mintun, A. M. Fagan et al., "Exercise and Alzheimer's disease biomarkers in cognitively normal older adults," Annals of Neurology, vol. 68, no. 3, pp. 311-318, 2010.

[103] A. M. Fagan, D. Head, A. R. Shah et al., "Decreased cerebrospinal fluid Abeta(42) correlates with brain atrophy in cognitively normal elderly," Annals of Neurology, vol. 65, no. 2, pp. 176-183, 2009.

[104] C. M. Gidicsin, J. E. Maye, J. J. Locascio et al., "Cognitive activity relates to cognitive performance but not to Alzheimer disease biomarkers," Neurology, vol. 85, no. 1, pp. 48-55, 2015.

[105] Z. Radak, S. Kumagai, A. W. Taylor, H. Naito, and S. Goto, "Effects of exercise on brain function: role of free radicals," Applied Physiology, Nutrition, and Metabolism, vol. 32, no. 5, pp. 942-946, 2007.

[106] N. C. Berchtold, G. Chinn, M. Chou, J. P. Kesslak, and C. W. Cotman, "Exercise primes a molecular memory for brainderived neurotrophic factor protein induction in the rat hippocampus," Neuroscience, vol. 133, no. 3, pp. 853-861, 2005.

[107] Y. H. Ding, J. Li, W. X. Yao, J. A. Rafols, J. C. Clark, and Y. Ding, "Exercise preconditioning upregulates cerebral integrins and enhances cerebrovascular integrity in ischemic rats," Acta Neuropathologica, vol. 112, no. 1, pp. 74-84, 2006.

[108] F. Sardi, L. Fassina, L. Venturini et al., "Alzheimer's disease, autoimmunity and inflammation. The good, the bad and the ugly," Autoimmunity Reviews, vol. 11, no. 2, pp. 149-153, 2011

[109] E. Blotnick and L. Anglister, "Exercise modulates synaptic acetylcholinesterase at neuromuscular junctions," Neuroscience, vol. 319, pp. 221-232, 2016.

[110] N. C. Berchtold, J. P. Kesslak, and C. W. Cotman, "Hippocampal brain-derived neurotrophic factor gene regulation by exercise and the medial septum," Journal of Neuroscience Research, vol. 68, no. 5, pp. 511-521, 2002. 


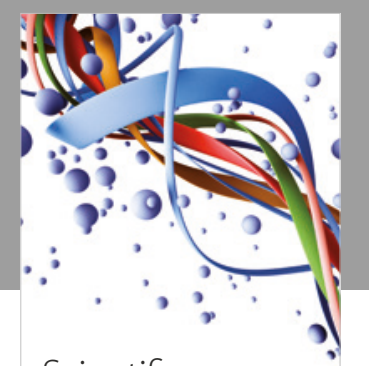

Scientifica
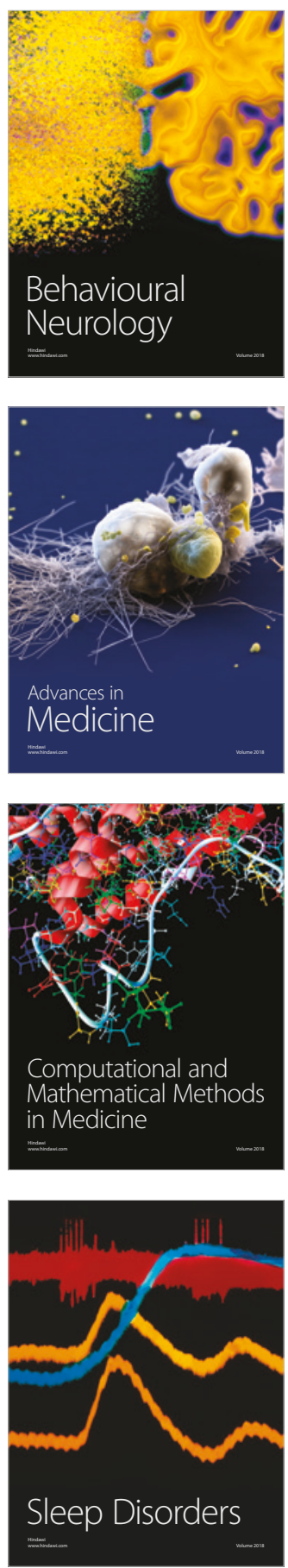

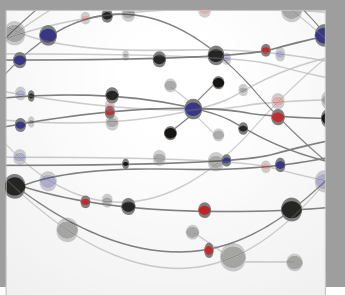

The Scientific World Journal

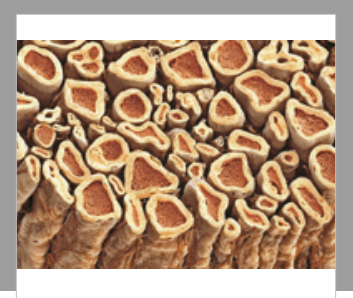

Case Reports in

Neurological Medicine

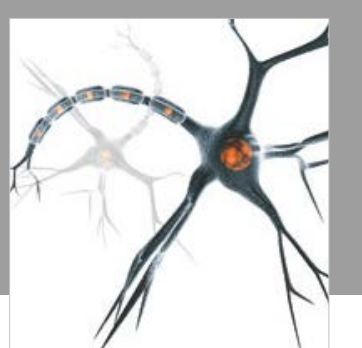

Neural Plasticity

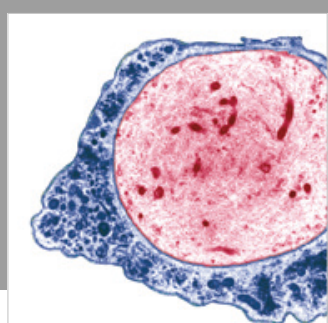

Multiple Sclerosis

International

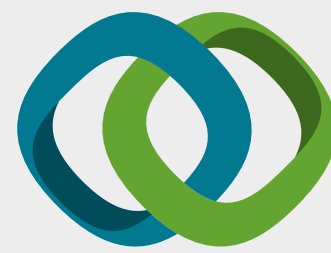

Hindawi

Submit your manuscripts at

www.hindawi.com
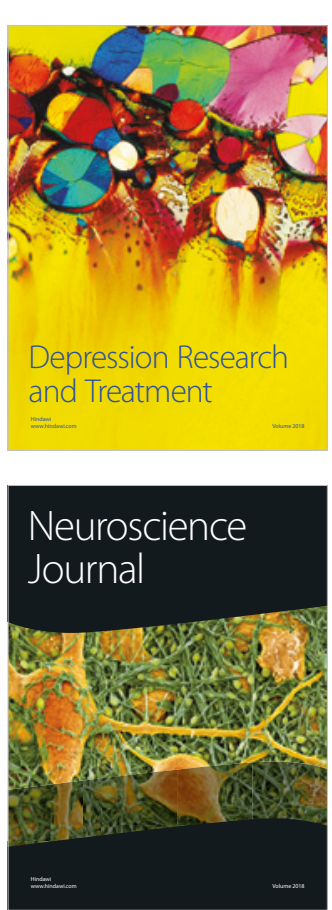

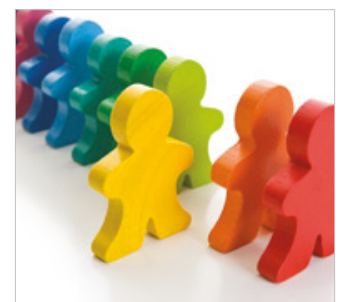

Autism

Research and Treatment
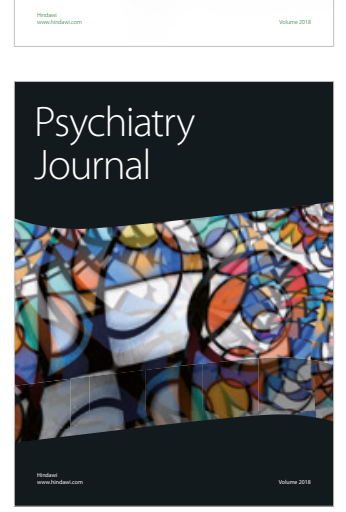
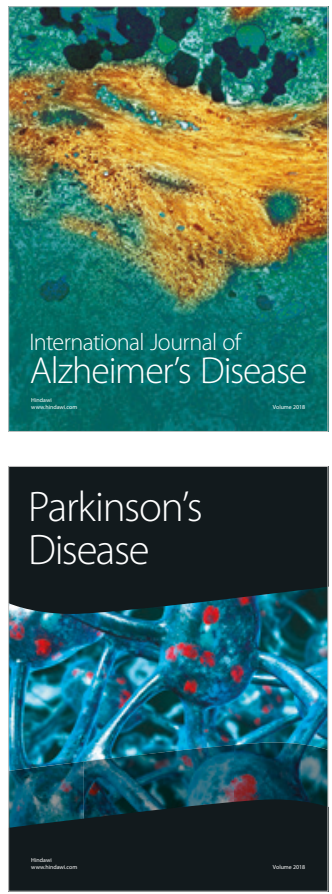
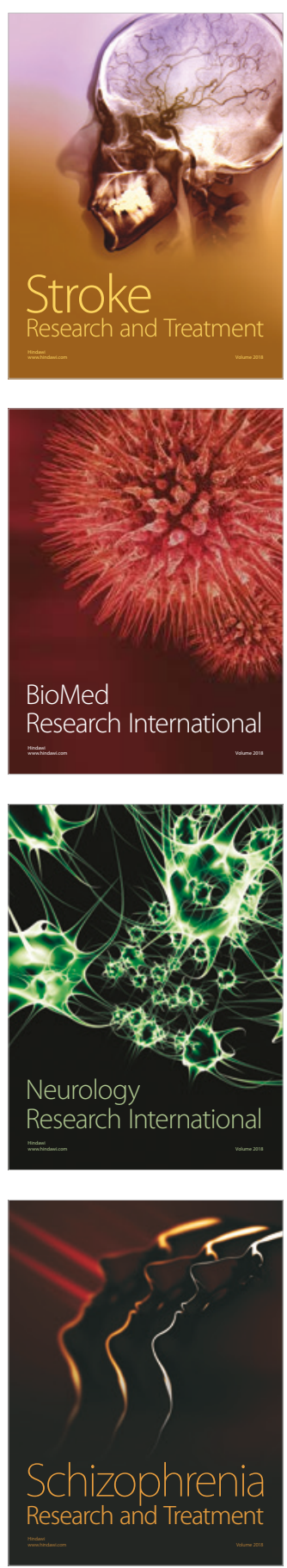